\title{
Poly(methyl methacrylate) (PMMA)-based hybrid materials with reactive zirconium oxide nanocrystals
}

\author{
Takeshi Otsuka, $^{1,2}$ and Yoshiki Chujo ${ }^{2}$
}

Highly transparent and homogeneous hybrids containing a single nano-sized inorganic oxide domain were synthesized from poly(methyl methacrylate) (PMMA) and aqueous dispersed zirconium oxide nanocrystals $\left(\mathrm{ZrO}_{2}-\mathrm{NCs}\right)$ in the presence of a coupling agent, 3-(methacryloxy)propyl-trimethoxysilane (MPTS), which was grafted onto the surface of $\mathrm{ZrO}_{2}-\mathrm{NCs}$ by zirconium hydroxide $(\mathrm{Zr}-\mathrm{OH})$ surface groups. The surface-functionalized $\mathrm{ZrO}_{2}-\mathrm{NCs}$ were used as macromonomers in the process of grafting from polymerization of methyl methacrylate (MMA). The densities of surface $\mathrm{Zr}$-OH groups and MPTS surface modifications were determined using thermogravimetric analysis. Fourier transform infrared analysis indicated successful bonding between organic and inorganic moieties. The morphology of the obtained hybrid films was investigated by scanning electron microscopy and tapping-mode atomic force microscopy. Hybrid films possess interesting thermal stability and optical transparency characteristics because of the uniform incorporation of networks between organic polymer chains and inorganic nanocrystals. Polymer Journal (2010) 42, 58-65; doi:10.1038/pj.2009.309

Keywords: macromonomer; nanocrystal; organic-inorganic hybrid; PMMA; transparency; $\mathrm{ZrO}_{2}$

\section{INTRODUCTION}

Organic-inorganic hybrid nanocomposite materials have been studied in recent years, with the expectation that nanocomposite materials will serve as an important and evolutionary means of achieving properties that cannot be realized with single materials. ${ }^{1-3}$ Composite materials with nanoscale domains show unique chemical and physical properties that are different from composites with microscale domains. ${ }^{4-6}$ Organic-inorganic hybrids, in which organic polymers are dispersed in the inorganic phase at the nanometer or molecular level, have been widely investigated because of the unique properties that result from nanometer-length scales, such as high gas-barrier properties and excellent solvent resistance, flame resistance and high transparency. Optical transparency is the most important characteristic of these hybrids and it arises because dispersion of material in the matrix is in the order of tens of nanometers, far less than the wavelength of visible and ultraviolet light. As a result, light is not lost due to scattering. ${ }^{\text {? }}$

The most simple and convenient idea for construction of transparent and homogeneous hybrid materials is to increase the affinity between organic polymer and inorganic phases. Organic-inorganic hybrid materials are generally prepared by incorporating covalent bonds $s^{8-13}$ or by physical interactions ${ }^{14-21}$ to improve the compatibility between organic and inorganic phases.

Poly(methyl methacrylate) (PMMA) is an excellent material because of its potential application in optical fibers, optical disks and lenses. When PMMA is combined with inorganic materials such as $\mathrm{SiO}_{2}, \mathrm{TiO}_{2}$ or zirconium oxide $\left(\mathrm{ZrO}_{2}\right)$ at the nanometer level, the resulting hybrid materials have high strength and thermal stability. ${ }^{22,23}$ In studies of PMMA/inorganic oxide materials, the inorganic network in hybrid materials is generally prepared from metal alkoxides ${ }^{24-26}$ or colloidal inorganic nanoparticles. ${ }^{27-30}$ There are many reports that base the preparation of $\mathrm{PMMA} / \mathrm{SiO}_{2}$ hybrid materials on unfunctionalized and trialkoxysilyl-functionalized acrylic polymers using an in situ sol-gel process in the presence of tetraethoxysilane (TEOS) or $\mathrm{Ti}(\mathrm{OBu})_{4}$. In this case, the polymerization of monomers and the hydrolysis and condensation of TEOS occur simultaneously. ${ }^{24-26,31-33}$ On the other hand, the colloidal silica approach provides the advantage of precise control on size distribution in hybrid materials. Colloidal silica with a particle size of $<100 \mathrm{~nm}$ is required to avoid light diffraction. Large particles with a high refractive index, such as $\mathrm{TiO}_{2}$ or $\mathrm{ZrO}_{2}$, result in optical scattering and material opacity, thus limiting the optical applications of these hybrid materials. Small particles with a diameter $<10 \mathrm{~nm}$ can avoid Rayleigh scattering and be incorporated into a polymer matrix while preserving optical transparency. There are a few reports of the synthesis of crystalline $\mathrm{ZrO}_{2}$ with an average particle size below $5 \mathrm{~nm}{ }^{34,35}$ Furthermore, in these reports, $\mathrm{ZrO}_{2}$ dispersions are colored, which restricts their application potential. Recently, because of improvements in manufacturing processes, we were able to obtain nonaggregated $\mathrm{ZrO}_{2}$ nanocrystals $(3 \mathrm{~nm})$ in an aqueous solution. ${ }^{36}$ This $\mathrm{ZrO}_{2}$ nanocrystal aqueous sol is colorless and suitable for use in the preparation of organic polymer and $\mathrm{ZrO}_{2}$ hybrid materials. ${ }^{37}$

Herein, we report the synthesis of $\mathrm{PMMA} / \mathrm{ZrO}_{2}$ nanocrystal $\left(\mathrm{ZrO}_{2}-\mathrm{NC}\right)$ hybrids with a coupling agent, 3-(methacryloxy)propyl- 
trimethoxysilane (MPTS), grafted onto the surface of $\mathrm{ZrO}_{2}-\mathrm{NCs}$ by zirconium hydroxide groups. The $\mathrm{ZrO}_{2}-\mathrm{NCs}$ functionalized with MPTS were used as macromonomers in the polymerization of methyl methacrylate (MMA). Turner et al. ${ }^{38,39}$ studied the characterization of MPTS grafted onto the surface of $\mathrm{ZrO}_{2}$ particles and found that organic silane molecules (MPTS) covalently bond to the surface of $\mathrm{ZrO}_{2}$ particles. However, in that study, the particles in the $\mathrm{ZrO}_{2}$ powder were relatively large, with an average diameter of $\sim 30 \mathrm{~nm}$, which is too large to be suitable for optical applications because of Rayleigh scattering.

In this paper, we modify $\mathrm{ZrO}_{2}$-NCs with MPTS for the polymerization of MMA, allowing for the covalent bonding of PMMA to $\mathrm{ZrO}_{2}$ particles and ultimately the fabrication of transparent $\mathrm{PMMA} / \mathrm{ZrO}_{2}-$ $\mathrm{NC}$ hybrid materials. $\mathrm{PMMA} / \mathrm{ZrO}_{2}-\mathrm{NC}$ hybrids, with hybrid domains in the order of a nanometer in size, show excellent transparency compared with that of PMMA/ZrO ${ }_{2}-\mathrm{NC}$ blend composites with larger domain sizes. We also investigate the reinforcement of PMMA with $\mathrm{ZrO}_{2}$ nanocrystals, which have excellent thermal stability. We show the potential of the transparent and homogeneous $\mathrm{PMMA} / \mathrm{ZrO}_{2}$ hybrids fabricated with inorganic nanocrystals for use in optical functional materials and coatings.

\section{EXPERIMENTAL PROCEDURE}

Materials

Methyl methacrylate monomer was purified by distillation under a vacuum. Azobisisobutyronitrile was recrystallized from ethanol at $35^{\circ} \mathrm{C}$. MPTS was purchased from Shin-Etsu Chemical (Tokyo, Japan). $\mathrm{ZrO}_{2}-\mathrm{NC}$ aqueous sols, containing $10.0 \mathrm{wt} \% \mathrm{ZrO}_{2}$ with chloride anion ( $\mathrm{pH}$ 2.0) and acetate anion
( $\mathrm{pH}$ 1.7), were obtained from Sumitomo Osaka Cement (Chiba, Japan). $\mathrm{ZrO}_{2}-$ NCs have a primary particle size of $3 \mathrm{~nm}$, with a particle size distribution in aqueous sols of $4.8 \pm 1.2 \mathrm{~nm} .{ }^{37}$ Methanol was dried and distilled from magnesium methoxide and stored under nitrogen. 2-Ethoxyethanol was distilled under reduced pressure and stored under nitrogen. The other reagents were used without further purification.

\section{Measurements}

Fourier transform infrared (FT-IR) spectra were obtained using a Perkin Elmer 2000 infrared spectrometer (PerkinElmer Inc., Waltham, MA, USA) using the $\mathrm{KBr}$ pellet method. Scanning electron microscopy (SEM) measurements were determined using a JSM-5600B system (JEOL, Tokyo, Japan). Surface images were measured using tapping-mode atomic force microscopy (TM-AFM) (SPA 400, SEIKO Instruments, Chiba, Japan) operating at room temperature. Height and phase images were recorded simultaneously using nanoprobe cantilevers (SI-DF20, SEIKO Instruments). Transmission electron microscopy (TEM) was performed with a JEM-100SX microscope (JEOL) at $100 \mathrm{kV}$. Specimens for sectional analysis were prepared using a focused ion beam (SMI2050, SEIKO Instruments). Differential scanning calorimetry thermograms were obtained with a DSC200 (SEIKO Instruments) at a heating rate of $10{ }^{\circ} \mathrm{C} \mathrm{min}-1$ under nitrogen atmosphere. Thermogravimetric analysis (TGA) was carried out using TGA/DTA6200 (SEIKO Instruments) at a heating rate of $10^{\circ} \mathrm{C} \mathrm{min}^{-1}$ in air. Ultraviolet-visible transmission spectra were measured with a model MPS-2000 multipurpose spectrometer (Shimadzu, Kyoto, Japan). Refractive index was determined by a model 2010 prism coupler (Metricon Corporation, Pennington, NJ, USA)

\section{Preparation of MPTS-modified $\mathrm{ZrO}_{2}$-NCs as macromonomers}

The preparation of MPTS-modified $\mathrm{ZrO}_{2}-\mathrm{NCs}$ is shown in Scheme 1 (a). $\mathrm{ZrO}_{2}$ $\mathrm{NC}$ aqueous sol was gradually replaced by methanol using a rotary evaporator.

a

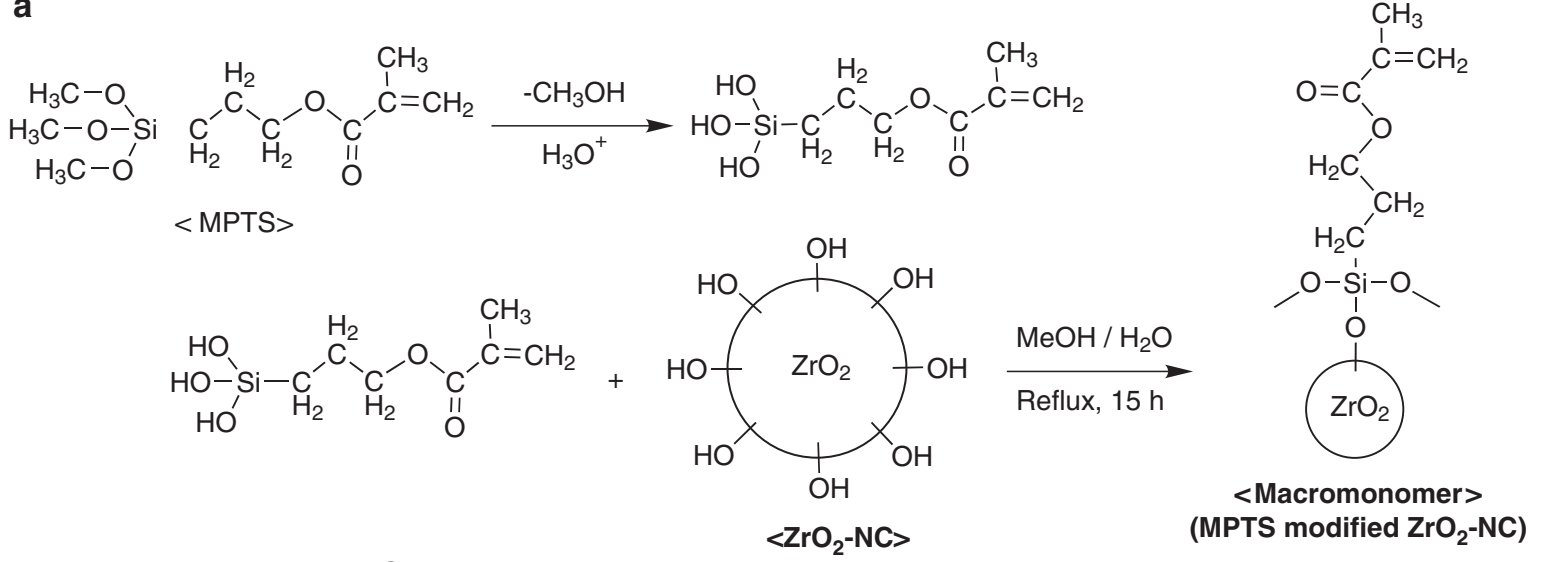

b<smiles>C=C(C)C(=O)OCCC[Si](OC)(OC)Oc1ccccc1</smiles><smiles>COC(=O)C(C)(CC(C)(C)C)CC(C)(C)CC(C)(CC(C)(C)C)C(=O)OCCC[Si](OC)(Oc1ccccc1)Oc1ccccc1</smiles>

Scheme 1 Reaction route for preparing (a) 3-(methacryloxy)propyl-trimethoxysilane (MPTS)-modified zirconium oxide nanocrystals ( $\mathrm{ZrO}_{2}-\mathrm{NCs}$ ) as macromonomers and (b) poly(methyl methacrylate) $(\mathrm{PMMA}) / \mathrm{ZrO}_{2}-\mathrm{NC}$ hybrid materials. 
Table 1 Synthesis of PMMA/ZrO 2 -NC hybrids

\begin{tabular}{|c|c|c|c|c|c|c|c|}
\hline Run & $\begin{array}{c}\mathrm{MMA} / \mathrm{MPTS}-\mathrm{ZrO} \mathrm{O}_{2} \\
\text { ratio }(\mathrm{mol} / \mathrm{mol})\end{array}$ & $M M A(m l)$ & $\begin{array}{l}\text { MPTS-modified } \\
\mathrm{ZrO}_{2}-\mathrm{NC}^{\mathrm{a}} \text { (mg) }\end{array}$ & $A / B N^{b}(m g)$ & $\begin{array}{l}\text { 2-Ethoxyethanol } \\
(\mathrm{ml})\end{array}$ & $\begin{array}{c}\text { Sol appearance after } \\
\text { polymerization }\end{array}$ & Film appearance \\
\hline 1 & $1 / 1$ & 0.055 & 250 & 5.06 & 10 & Precipitate & Crumble \\
\hline 3 & $10 / 1$ & 0.547 & 250 & 27.85 & 10 & Translucent & Transparent \\
\hline 4 & $25 / 1$ & 1.369 & 250 & 65.84 & 10 & Transparent & Transparent \\
\hline $5^{c}$ & $1 / 0$ & 1.507 & 0 & 69.69 & 10 & Transparent & Transparent \\
\hline
\end{tabular}

Abbreviations: AIBN, azobisisobutyronitrile; MMA, methyl methacrylate; MPTS, 3-(methacryloxy)propyl-trimethoxysilane; PMMA, poly(methyl methacrylate); ZrO 2 -NCs, zirconium oxide nanocrystals. ${ }^{a}$ MPTS-modified $\mathrm{ZrO}_{2}-\mathrm{NC}$ (Table 3, M-3) was used.

${ }^{\mathrm{b}} \mathrm{AIBN} /(\mathrm{MMA}+\mathrm{MPTS})=3.0 \mathrm{~mol} \%$.

' 8.35 wt $\%$ of PMMA solution was obtained.

Table 2 Preparation of PMMA/ZrO $2-\mathrm{NC}$ blend composites ${ }^{\mathrm{a}}$

\begin{tabular}{lccccc}
\hline Run & $\begin{array}{c}\text { PMMA } \\
\text { solution }^{\text {b }}(\mathrm{g})\end{array}$ & $\begin{array}{c}\text { Surface-modified } \\
\mathrm{ZrO}_{2}-\mathrm{NC}(\mathrm{mg})\end{array}$ & $\begin{array}{c}\text { Surface } \\
\text { modifier }\end{array}$ & $\begin{array}{c}\text { Sol } \\
\text { appearance }\end{array}$ & $\begin{array}{c}\text { Film } \\
\text { appearance }\end{array}$ \\
\hline 6 & 1.00 & 100 & Acetate anion $^{\mathrm{c}}$ & Transparent \\
7 & 0.70 & 100 & MPTS $^{\mathrm{d}}$ & Transparent & Translucent \\
\hline
\end{tabular}

Abbreviations: MPTS, 3-(methacryloxy)propyl-trimethoxysilane; PMMA, poly(methy methacrylate); $\mathrm{ZrO}_{2}-\mathrm{NCs}$, zirconium oxide nanocrystals.

${ }^{a}$ Compositions of PMMA and $\mathrm{ZrO}_{2}$-NCs were fixed about $35 \mathrm{wt} \%$ ceramic yields.

bPMMA solution (Table 1, Run 5) was used.

${ }^{\mathrm{C}} \mathrm{The} \mathrm{ZrO}_{2}$-NC powder, which was obtained from evaporation of aqueous sol with acetate anion

$(\mathrm{pH} 1.7)$, was used. The amount of surface attached acetate anion was $19.7 \mathrm{wt} \%$ by thermogravimetric analysis.

${ }^{d}$ MPTS-modified $\mathrm{ZrO}_{2}$-NCs (Table 3, M-3) was used.

The transparent methanol/water solution with $2.5 \mathrm{wt} \% \mathrm{ZrO}_{2}-\mathrm{NC}$ was cooled in an ice-cold water bath with vigorous stirring under nitrogen atmosphere. MPTS was added dropwise to the $\mathrm{ZrO}_{2}$-NC solution using a syringe inserted through a septum and the reaction mixture was stirred for $30 \mathrm{~min}$. The feed mole ratios of MPTS to $\mathrm{ZrO}_{2}$ were $0.25-0.50$ to 1.0. The mixture was then refluxed and stirred vigorously for $15 \mathrm{~h}$, at which point the solution seemed slightly smoky. The resulting solution was concentrated and the residue was poured into water to precipitate the reactant. The MPTS-modified $\mathrm{ZrO}_{2}-\mathrm{NCs}$ precipitate was filtered, carefully washed with a water/methanol solution and dried in vacuum at $30^{\circ} \mathrm{C}$.

\section{Synthesis of PMMA/ZrO ${ }_{2}$-NC hybrid sols}

The polymerization of MMA with macromonomers is shown in Scheme 1(b). Under a nitrogen atmosphere, the obtained MPTS-modified $\mathrm{ZrO}_{2}$-NCs (serving as a macromonomer), MMA monomer and azobisisobutyronitrile were dissolved in 2-ethoxyethanol at the compositions shown in Table 1 and stirred for $1 \mathrm{~h}$ at room temperature. The resulting solution was heated to begin the radical polymerization reaction. The reaction temperature was maintained at $60^{\circ} \mathrm{C}$ and the solution was stirred under a nitrogen flow for $2 \mathrm{~h}$ to obtain the PMMA/ZrO ${ }_{2}-\mathrm{NC}$ hybrid sol.

\section{Preparation of $\mathrm{PMMA} / \mathrm{ZrO}_{2}-\mathrm{NC}$ hybrid films}

The PMMA/ZrO ${ }_{2}-\mathrm{NC}$ hybrid films were prepared as follows. The PMMA/ $\mathrm{ZrO}_{2}-\mathrm{NC}$ hybrid sol was cast in a PFA container and cured at $60^{\circ} \mathrm{C}$ for $30 \mathrm{~min}$, at $90^{\circ} \mathrm{C}$ for $30 \mathrm{~min}$ and then at $120^{\circ} \mathrm{C}$ for $1 \mathrm{~h}$. Hybrid thin films $\sim 2 \mu \mathrm{m}$ thick were formed on a quartz glass substrate by spin coating to characterize the optical transmittance and refractive index.

We also investigated the difference between the thermal and optical properties of hybrid films and blend composite films. $\mathrm{ZrO}_{2}-\mathrm{NCs}$ with acetate anion obtained from $\mathrm{ZrO}_{2}-\mathrm{NC}$ aqueous sol, the MPTS-modified $\mathrm{ZrO}_{2}-\mathrm{NCs}$ and PMMA sol (Table 1, Run 5) were mixed, stirred for $30 \mathrm{~min}$ and formed into blend composite films, as described above. The compositions of the blend composites are shown in Table 2. The curing process was the same as that for $\mathrm{PMMA} / \mathrm{ZrO}_{2}-\mathrm{NC}$ hybrid films.

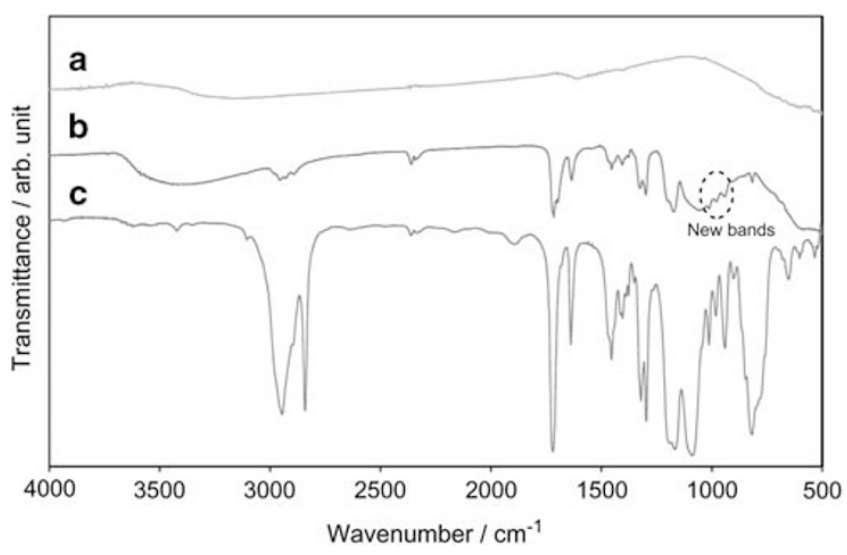

Figure 1 Fourier transform infrared (FT-IR) spectra of (a) bare zirconium oxide nanocrystals $\left(\mathrm{ZrO}_{2}-\mathrm{NCs}\right)$, (b) 3-(methacryloxy)propyl-trimethoxysilane (MPTS)-modified $\mathrm{ZrO}_{2}-\mathrm{NCs}$ and (c) MPTS.

\section{RESULTS AND DISCUSSION}

Characterization of MPTS-modified $\mathrm{ZrO}_{2}$-NCs as macromonomers FT-IR spectra of MPTS-modified $\mathrm{ZrO}_{2}$-NCs and pure ligands are presented in Figure 1. A spectrum obtained from bare $\mathrm{ZrO}_{2}-\mathrm{NCs}$ is shown for comparison. The major peaks that can be attributed to MPTS (Figure 1c) are the ester functionality at 1295 and $1320 \mathrm{~cm}^{-1}$, the ester vibrations (C-O-C in the ester group) at 1156 and $1179 \mathrm{~cm}^{-1}$, the vinyl $\mathrm{C}=\mathrm{C}$ stretching mode at $1637 \mathrm{~cm}^{-1}$, the carbonyl $\mathrm{C}=\mathrm{O}$ stretching mode at $1716 \mathrm{~cm}^{-1}$ and the $\mathrm{C}-\mathrm{H}$ stretching vibrations at $2840-3000 \mathrm{~cm}^{-1}$. The bands at $500-850 \mathrm{~cm}^{-1}$ and $1050-1110 \mathrm{~cm}^{-1}$ are due to $\mathrm{Zr}-\mathrm{O}$ and $\mathrm{Si}-\mathrm{O}$ bonds, respectively. The spectrum of MPTS-modified $\mathrm{ZrO}_{2}-\mathrm{NCs} \quad\left(\mathrm{MPTS} / \mathrm{ZrO}_{2}=\right.$ $6.04 / 12.2 \mathrm{mmol}$ ) in Figure $1 \mathrm{~b}$ shows bands in the range of 800 $1100 \mathrm{~cm}^{-1}$ that arise due to the Si-O-Zr bond. This indicates the formation of a chemical bond between $\mathrm{ZrO}_{2}$ and MPTS ligands. MPTS molecules form a chemical bond to the metal oxide surface, which is thought to progress because of the hydrolysis of one or more of the alkoxy groups, followed by condensation with surface hydroxyl groups. The band in the MPTS-modified $\mathrm{ZrO}_{2}$-NCs spectrum occurring at $1640-1750 \mathrm{~cm}^{-1}$ (Figure $1 \mathrm{~b}$ ) reveals that the absorption peak associated with the carbonyl group of surface-bound MPTS splits into two peaks, one strong peak at $1713 \mathrm{~cm}^{-1}$ and one shoulder at $1693 \mathrm{~cm}^{-1}$, corresponding to the vibration of free and associated carbonyl groups, respectively. The association of carbonyl groups is probably caused by the surface hydroxyl groups of $\mathrm{ZrO}_{2}-\mathrm{NCs}$ or by the residual silanol groups of MPTS, namely, hydrogen-bonding interactions. 
Thermogravimetric analysis was used to quantify the density of hydroxyl groups on $\mathrm{ZrO}_{2}-\mathrm{NCs}$ (Figure 2a). According to reports in the literature, ${ }^{40,41}$ physically adsorbed water can be removed at $120^{\circ} \mathrm{C}$, indicating that weight loss above $120^{\circ} \mathrm{C}$ resulted from the removal of hydroxyl groups on the $\mathrm{ZrO}_{2}-\mathrm{NC}$ surface. Weight loss could potentially arise from the desorption of volatile organic compounds left from particle processing; however, FT-IR spectra (Figure 1a) confirmed that there were no volatile organic compounds on the particles. A value of $9.7 \mathrm{OH} \mathrm{nm}^{-2}$ calculated using TGA weight loss and specific surface areas was obtained, which is comparable to the previously mentioned values of $10.3-10.8 \mathrm{OH} \mathrm{nm}^{-2}$ for $\mathrm{ZrO}_{2} \cdot{ }^{38,41}$ The significant mass loss in the TGA of MPTS-modified $\mathrm{ZrO}_{2}-\mathrm{NCs}$ (MPTS/ $\mathrm{ZrO}_{2}=6.04 / 12.2 \mathrm{mmol}$, Figure $2 \mathrm{~b}$ ) indicated that the grafting of MPTS on treated $\mathrm{ZrO}_{2}$ nanocrystals was successful. Quantification of the amount of grafted MPTS was calculated from TG mass losses, assuming that thermal degradation begins with methacrylic acid loss, followed by allylic radical loss. The loss of methacrylic acid above $150{ }^{\circ} \mathrm{C}$ and the loss of allylic radicals above $250{ }^{\circ} \mathrm{C}$ were confirmed,

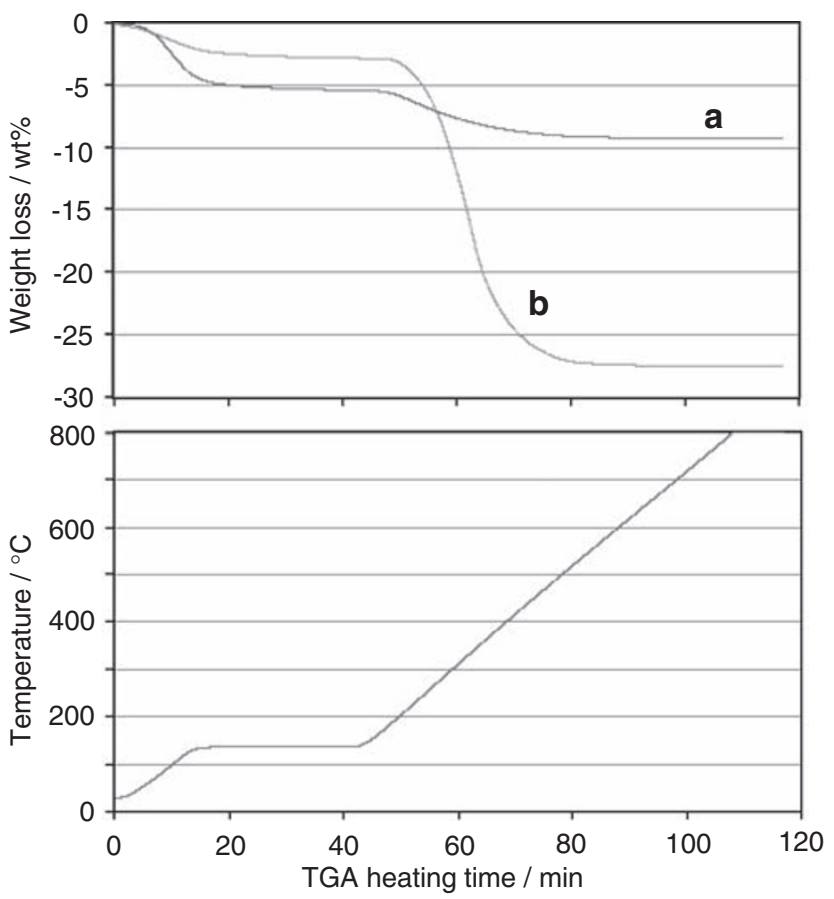

Figure 2 Thermogravimetric analysis (TGA) comparisons of (a) pure zirconium oxide nanocrystals ( $\mathrm{ZrO}_{2}-\mathrm{NCs}$ ) and (b) 3-(methacryloxy)propyltrimethoxysilane (MPTS)-modified $\mathrm{ZrO}_{2}$-NCs (Table 1, Run 4). The diagram indicates the TGA temperature profile. and the weight loss above $150{ }^{\circ} \mathrm{C}$ was therefore attributed to the pyrolysis of the organic component of MPTS. TGA of MPTS yielded a value of $6.82-12.1 \mathrm{MPTS} \mathrm{nm}^{-2}\left(11.3-20.1 \mu \mathrm{mol} \mathrm{m}^{-2}\right.$, Table 3), which was higher than the previously published values of 1.73.4 MPTS nm ${ }^{-2}\left(2.8-5.7 \mu \mathrm{mol} \mathrm{m}^{-2}\right)$ for $\mathrm{ZrO}_{2}{ }^{38}$ The amount of grafted MPTS gradually increased with the amount of MPTS used during processing, as seen in Table 3. If we assume that MPTS has a molecular area of $0.60 \mathrm{~nm}^{2}, 42$ a single coating of the silane would result in a maximum surface density of $1.7 \mathrm{MPTS} \mathrm{nm}^{-2}$ $\left(2.8 \mu \mathrm{mol} \mathrm{m}^{-2}\right)$. As calculations indicated a much higher density, this suggests either the formation of MPTS multicoatings or the aggregation of MPTS on the surface. The excess water that exists in the reaction solution suggests that MPTS homopolymerization also took place.

From FT-IR analysis (Figure 1), we know that the Zr-O-Si chemical bonding is the primary force holding the molecule at the surface. Hydrogen bonding through a carbonyl group has only a minor role, as indicated by FT-IR spectroscopy data (Figure 1b). The improvement in interface adhesion between $\mathrm{ZrO}_{2}$-NC and the matrix was established by covalent bonding between the two phases. Thus, MPTSmodified $\mathrm{ZrO}_{2}$-NCs could be used as macromonomers in grafting from the polymerization of organic monomers.

\section{Characterization of PMMA/ZrO ${ }_{2}-\mathrm{NC}$ hybrid sols}

The PMMA/Z $\mathrm{ZO}_{2}-\mathrm{NC}$ hybrid sols were synthesized using a radical polymerization reaction of MMA monomer, MPTS-modified $\mathrm{ZrO}_{2}-$ $\mathrm{NC}$ as a macromonomer and 2-ethoxyethanol as a solvent. We used MPTS-modified $\mathrm{ZrO}_{2}$ powder with $2.06 \mathrm{mmolg}^{-1}$ of MPTS molecules (Table 3, M-3). The results obtained from hybrids with surfacepolymerized $\mathrm{ZrO}_{2}$-NCs are summarized in Table 1 . The $\mathrm{PMMA} / \mathrm{ZrO}_{2}-$ $\mathrm{NC}$ hybrid sols with a high $\mathrm{ZrO}_{2}-\mathrm{NC}$ content had precipitates consisting of PMMA and $\mathrm{ZrO}_{2}-\mathrm{NCs}$ aggregates (Table 1, Run 1). However, the dispersivity of $\mathrm{ZrO}_{2}$-NCs for the sample with an MMA/ MPTS molar ratio of 5:1 was clearly improved, and the material was translucent (Run 2). For the sample with an MMA/MPTS molar ratio of 10:1, the transparency of hybrid sols was considerably improved, and homogeneous $\mathrm{PMMA} / \mathrm{ZrO}_{2}-\mathrm{NC}$ hybrid sols were obtained (Run $3,4)$. This indicates an improvement in the dispersion stability for $\mathrm{ZrO}_{2}$-NCs in hybrid sols, most likely arising from the protective effect of PMMA polymer chains that resulted from polymerization of MMAs. A control sample of PMMA without $\mathrm{ZrO}_{2}$ was transparent, confirming the good film-forming property of the PMMA homopolymer (Run 5).

The homogeneity of hybrid sols with PMMA was examined by TEM (Figure 3) and ultraviolet-visible transmittance (Figure 4) measurements. As shown in Figure 3a, the obtained MPTS-modified $\mathrm{ZrO}_{2^{-}}$ NCs were easily dispersed in 2-ethoxyethanol, although unmodified

Table 3 Hydroxyl groups and grafted MPTS surface densities for $\mathrm{ZrO}_{2}-\mathrm{NCs}^{\mathrm{a}}$

MPTS surface densities

\begin{tabular}{|c|c|c|c|c|}
\hline $\begin{array}{l}\text { Sample } \\
\text { name }\end{array}$ & $\begin{array}{l}\text { Hydroxyl groups surface densities } \\
\text { measured by TGA }\left(\mathrm{OH} \mathrm{nm}^{-2}\right)\end{array}$ & $\begin{array}{l}\text { Added amount } \\
\left(\text { MPTS } n m^{-2}\right)\end{array}$ & $\begin{array}{l}\text { Grafted amount measured } \\
\left.\text { by TGA (MPTS } n m^{-2}\right)^{b}\end{array}$ & $\begin{array}{l}\text { Dispersivity to } \\
\text { 2-ethoxyethanol }\end{array}$ \\
\hline$M-1$ & & $7.15\left(11.9 \mu \mathrm{mol} \mathrm{m}^{-2}\right)$ & $6.82\left(11.3 \mu \mathrm{mol} \mathrm{m}{ }^{-2}\right)$ & Turbid \\
\hline$M-2$ & $9.72\left(16.1 \mu \mathrm{mol} \mathrm{m}^{-2}\right)^{\mathrm{c}}$ & $10.7\left(17.8 \mu \mathrm{mol} \mathrm{m}^{-2}\right)$ & $9.10\left(15.1 \mu \mathrm{mol} \mathrm{m}{ }^{-2}\right)$ & Transparent \\
\hline$M-3$ & & $14.3\left(23.7 \mu \mathrm{mol} \mathrm{m}^{-2}\right)$ & $12.1\left(20.1 \mu \mathrm{mol} \mathrm{m}{ }^{-2}\right)$ & Transparent \\
\hline
\end{tabular}

Abbreviations: MPTS, 3-(methacryloxy)propyl-trimethoxysilane; TGA, thermogravimetric analysis; $\mathrm{ZrO}_{2}-\mathrm{NCs}$, zirconium oxide nanocrystals.

aspecific surface area of $\mathrm{ZrO}_{2}$-NCs was $170 \mathrm{~m}^{2} \mathrm{~g}^{-1}$ from our previous report. ${ }^{37}$

bGrafted MPTS molecule onto $\mathrm{ZrO}_{2}-\mathrm{NC}$ was assumed as completely cross-linked silane, ' $\mathrm{CH}_{2}\left(\mathrm{CH}_{3}\right) \mathrm{C}(\mathrm{CO}) \mathrm{OC}_{3} \mathrm{H}_{6} \mathrm{SiO}_{1.5}$ ', and then forming inorganic $\mathrm{SiO}{ }_{2}$ after pyrolysis of organic component.

'Data were calculated by the weight loss of $120-800^{\circ} \mathrm{C}$ of pure $\mathrm{ZrO}_{2}-\mathrm{NCs}$, assuming that the surface of $\mathrm{ZrO}_{2}-\mathrm{NC}$ is free of $\mathrm{OH}$ surface groups at $800{ }^{\circ} \mathrm{C}$. 

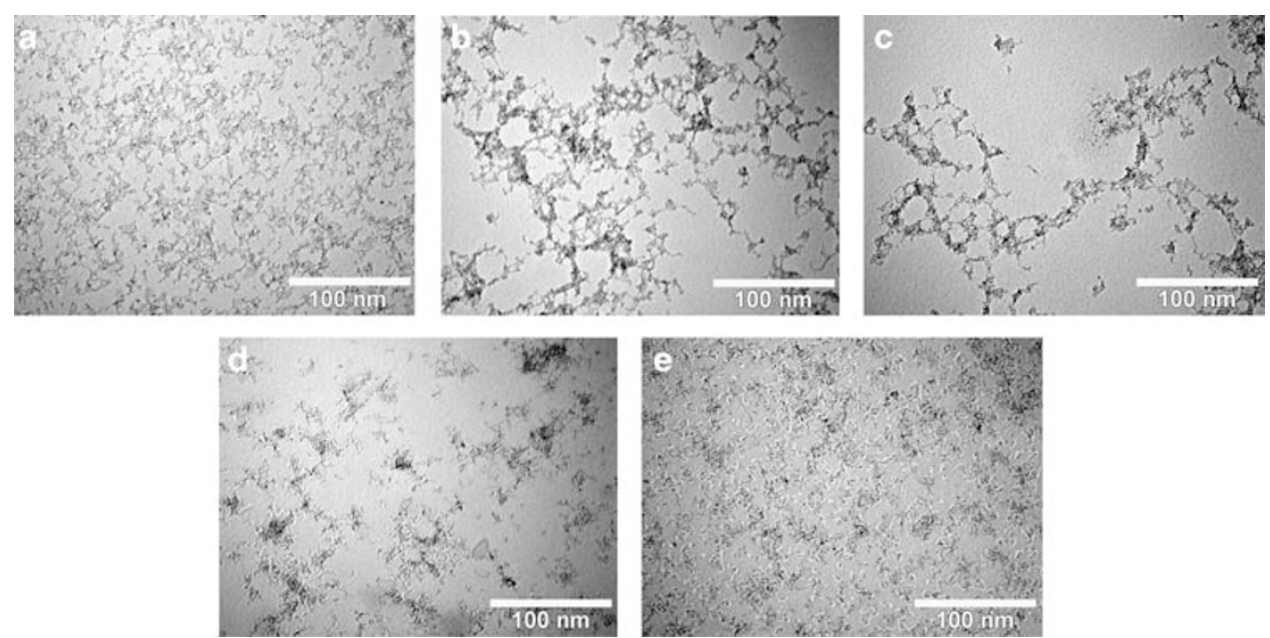

Figure 3 Transmission electron microscopy images of hybrid sols for (a) 3-(methacryloxy)propyl-trimethoxysilane (MPTS)-modified zirconium oxide nanocrystals $\left(\mathrm{ZrO}_{2}-\mathrm{NCs}\right.$ ), (b) methyl methacrylate (MMA)/MPTS- $\mathrm{ZrO}_{2}=1 / 1$ (Run 1), (c) $\mathrm{MMA} / \mathrm{MPTS}-\mathrm{ZrO}_{2}=5 / 1$ (Run 2), (d) $\mathrm{MMA} / \mathrm{MPTS}-\mathrm{ZrO}{ }_{2}=10 / 1$ (Run 3) and (e) MMA/MPTS-ZrO $2=25 / 1$ (Run 4).

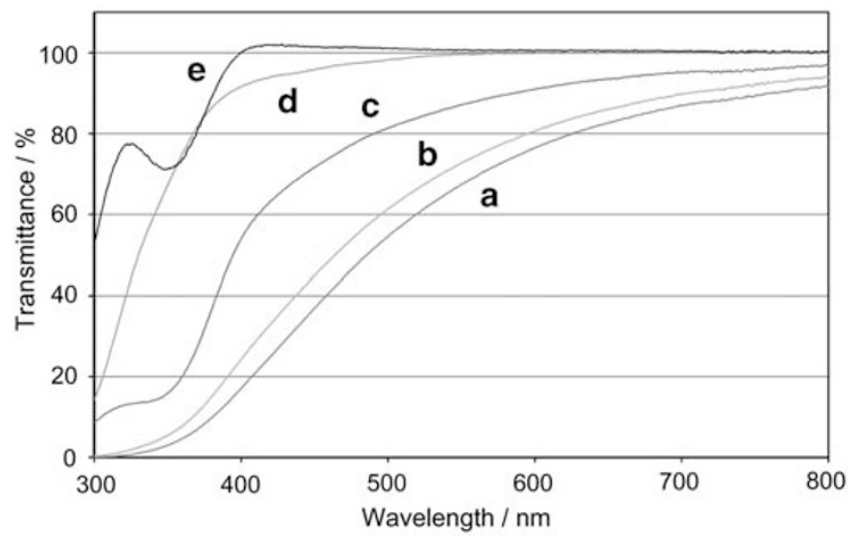

Figure 4 Optical transmittance of hybrid sols for (a) methyl methacrylate (MMA)/3-(methacryloxy)propyl-trimethoxysilane (MPTS)-zirconium oxide $\left(\mathrm{ZrO}_{2}\right)=5 / 1$ (Run 2), (b) MMA/MPTS- $\mathrm{ZrO}_{2}=10 / 1$ (Run 3), (c) MMA/MPTS$\mathrm{ZrO}_{2}=25 / 1$ (Run 4), (d) MPTS-modified $\mathrm{ZrO}_{2}$ nanocrystals ( $\mathrm{ZrO}_{2}-\mathrm{NCs}$ ) and (e) homopolymerized poly(methyl methacrylate) (PMMA) (Run 5). Operating light transmittance length was $10 \mathrm{~mm}$.

$\mathrm{ZrO}_{2}$-NCs could not be dispersed in this medium. This result indicates that heating during the modification reaction caused MPTS molecules to attach to $\mathrm{ZrO}_{2}-\mathrm{NCs}$, increasing the solubility of $\mathrm{ZrO}_{2}$-NCs in 2-ethoxyethanol. On the other hand, the sample with an MMA/MPTS molar ratio of 1:1 (Figure $3 b$ ), fabricated by the radical polymerization of MMA with MPTS-modified $\mathrm{ZrO}_{2}-\mathrm{NCs}$, contained aggregates resulting from nanocrystal cross-linking. These aggregates were also clearly seen in TEM images of hybrid MMA/MPTS with a molar ratio of 5:1 (Run 2, Figure 3c). However, in the translucent hybrid sol with an MMA/MPTS molar ratio of 10:1 (Run 3), homogeneity was clearly increased. A small amount of cross-linking was also observed by TEM (Figure 3d). In the hybrid sol with an MMA/MPTS molar ratio of 25:1, these assemblies disappeared (Figure 3e). This indicates that the dispersion stability for $\mathrm{ZrO}_{2}$ NCs in hybrid sols is improved, which can be attributed to the increased protective effect of PMMA polymer chains.

The homogeneity of $\mathrm{PMMA} / \mathrm{ZrO}_{2}-\mathrm{NC}$ hybrid sols was examined by ultraviolet-visible transmittance (Figure 4). The translucent hybrid sols (Run 2,3) showed low transmittance in the region of visible light
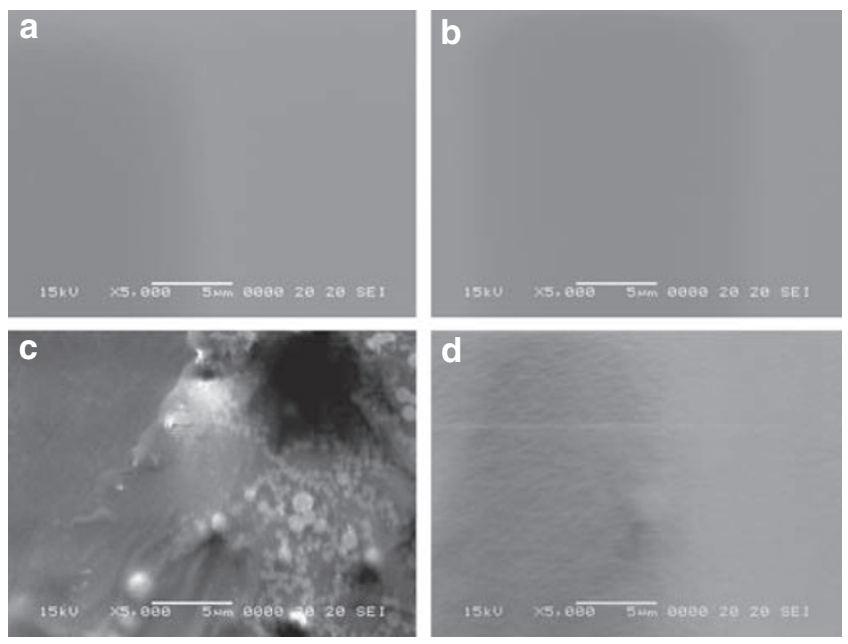

Figure 5 Scanning electron microscopy images of poly(methyl methacrylate) (PMMA)/zirconium oxide nanocrystal $\left(\mathrm{ZrO}_{2}-\mathrm{NC}\right)$ hybrids for (a) a methyl methacrylate (MMA)/3-(methacryloxy)propyl-trimethoxysilane (MPTS)-ZrO molar ratio of 10:1 (Run 3 ) and (b) an MMA/MPTS-ZrO 2 molar ratio of 25:1 (Run 4), and PMMA blend composite for (c) acetate anion-modified $\mathrm{ZrO}_{2}$ NCs (Run 6) and (d) MPTS-modified $\mathrm{ZrO}_{2}-\mathrm{NCs}$ (Run 7).

because of scattering loss caused by the aggregates of cross-linked nanocrystals. Transparency was improved in the hybrid sol that had a high PMMA (Figure 4c) content, making it more suitable as an optical transparent hybrid material. Using MPTS-modified $\mathrm{ZrO}_{2}-\mathrm{NCs}$ as macromonomers, $\mathrm{PMMA} / \mathrm{ZrO}_{2}-\mathrm{NC}$ hybrid sols with controlled dispersion of $\mathrm{ZrO}_{2}$-NCs in the PMMA matrix were obtained.

\section{Characteristic comparisons between $\mathrm{PMMA} / \mathrm{ZrO}_{2}-\mathrm{NC}$ hybrids and blend composites}

The PMMA/Z $\mathrm{rO}_{2}-\mathrm{NC}$ hybrid films were formed by first casting hybrid sols (Table 1, Run 1-5) and then heating them to evaporate the solvent. Blend composite films were prepared as mentioned above. The compositions of blend composites are shown in Table 2.

The dispersivity of the PMMA and $\mathrm{ZrO}_{2}$ phases was examined by SEM (Figure 5). Phase separation of the blend composite with acetate anion-modified $\mathrm{ZrO}_{2}$-NCs (Run 6) was observed (Figure 5c). Bright 

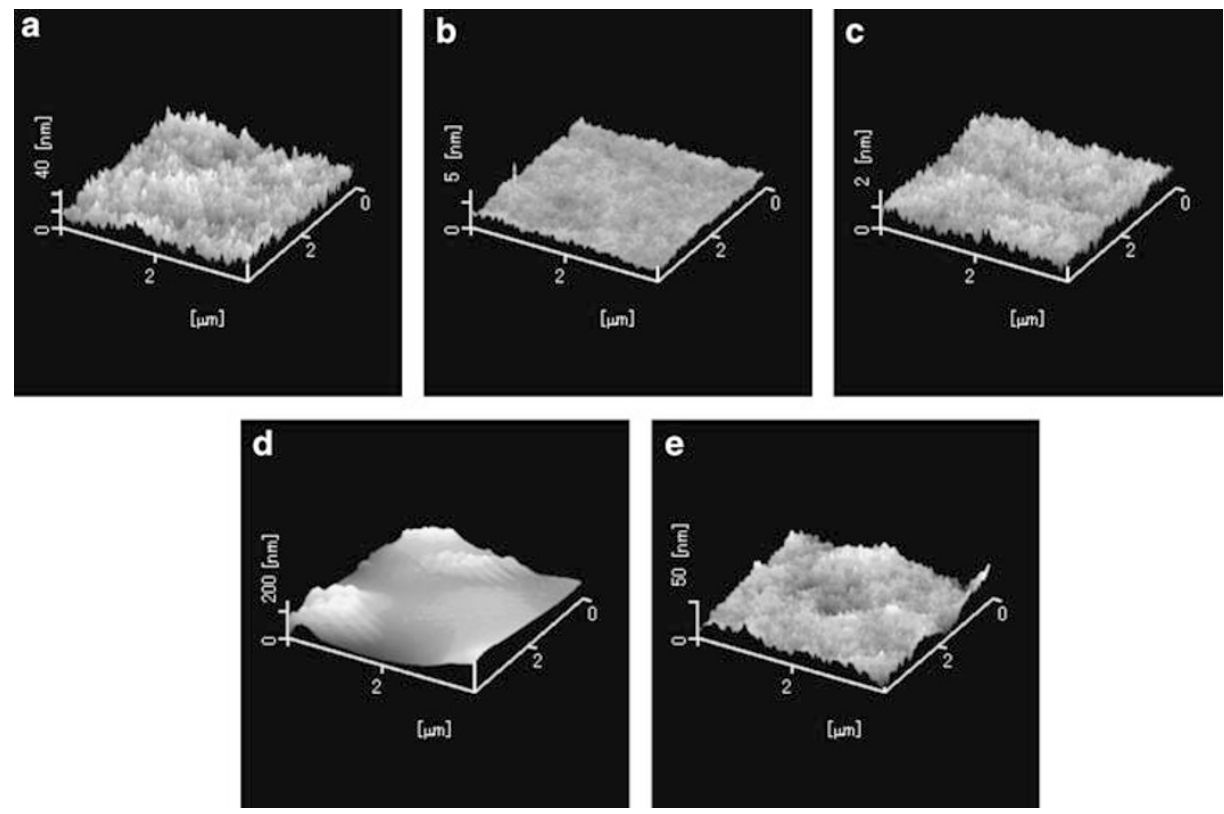

Figure 6 Tapping-mode atomic force microscopy (TM-AFM) images of (a) methyl methacrylate (MMA)/3-(methacryloxy)propyl-trimethoxysilane (MPTS)zirconium oxide $\left(\mathrm{ZrO}_{2}\right.$ ), molar ratio of 10:1 (Run 3), (b) MMA/MPTS- $\mathrm{ZrO}_{2}$, molar ratio of 25:1 (Run 4) and (c) poly(methyl methacrylate) (PMMA) homopolymer (Run 5), and PMMA blend composite for (d) acetate anion-modified $\mathrm{ZrO}_{2}$ nanocrystals $\left(\mathrm{ZrO}_{2}-\mathrm{NCs}\right)(\mathrm{Run} 6)$ and (e) MPTS-modified $\mathrm{ZrO}{ }_{2}-\mathrm{NCs}$ (Run 7).

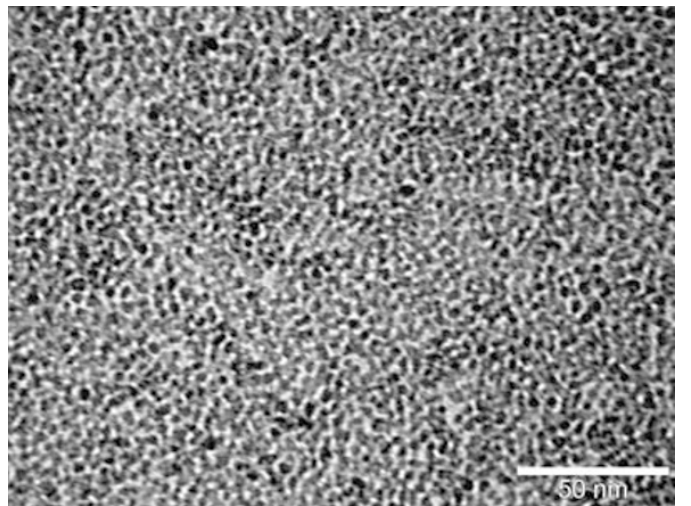

Figure 7 Transmission electron microscopy image of methyl methacrylate (MMA)/3-(methacryloxy)propyl-trimethoxysilane (MPTS)-zirconium oxide $\left(\mathrm{ZrO}_{2}\right)$, molar ratio of 10:1 (Run 3).

spots indicate $\mathrm{ZrO}_{2}-\mathrm{NC}$ aggregates. In Figure 5d, small surface asperities confirm the slight miscibility difference between PMMA chains and MPTS-modified $\mathrm{ZrO}_{2}-\mathrm{NCs}$, which can be attributed to the poor chemical interaction for each component. In contrast, in the case of PMMA $/ \mathrm{ZrO}_{2}-\mathrm{NC}$ hybrids (Run 3,4), $\mathrm{ZrO}_{2}-\mathrm{NCs}$ are dispersed completely (Figures $5 \mathrm{a}$ and $\mathrm{b}$ ). It is thus expected that $\mathrm{ZrO}_{2}-\mathrm{NCs}$ are dispersed at the nanometer level.

The homogeneity of hybrids and blend composites was examined by TM-AFM (Figure 6). The blend composite of PMMA and acetate anion-modified $\mathrm{ZrO}_{2}$-NCs (Run 6) showed high surface roughness (Figure 6d). In Figure 6e, the blend composite of PMMA and MPTSmodified $\mathrm{ZrO}_{2}-\mathrm{NCs}$ (Run 7) exhibited a crenellated surface topology. On the other hand, the surfaces of $\mathrm{PMMA} / \mathrm{ZrO}_{2}-\mathrm{NC}$ hybrids (Figures $6 \mathrm{a}$ and b, Run 3, 4) and PMMA homopolymer (Figure 6c, Run 5) were extremely smooth, although surface roughness was shown to increase

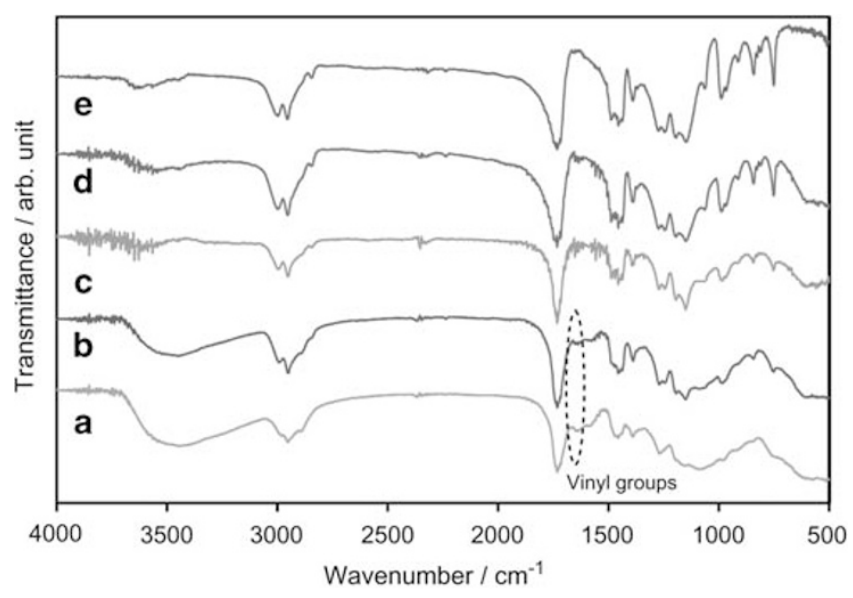

Figure 8 Fourier transform infrared (FT-IR) spectra of (a) methyl methacrylate (MMA)/3-(methacryloxy)propyl-trimethoxysilane (MPTS)zirconium oxide $\left(\mathrm{ZrO}_{2}\right)$, molar ratio of $1: 1$ (Run 1 ), (b) MMA/MPTS- $\mathrm{ZrO}_{2}$, molar ratio of 5:1 (Run 2), (c) MMA/MPTS-ZrO ${ }_{2}$, molar ratio of 10:1 (Run 3), (d) MMA/MPTS-ZrO 2 , molar ratio of 25:1 (Run 4) and (e) poly(methyl methacrylate) (PMMA) homopolymer (Run 5).

slightly with an increasing amount of $\mathrm{ZrO}_{2}$-NCs. As shown in Figure 7, $\mathrm{ZrO}_{2}$-NCs were well dispersed in the PMMA polymer matrix. TMAFM and TEM observations further support the hypothesis that covalent bonding between PMMA and MPTS-modified $\mathrm{ZrO}_{2}-\mathrm{NC}$ as a macromonomer is crucial to obtain nanoscale dispersed hybrid materials.

Figure 8 shows the FT-IR spectra of $\mathrm{PMMA} / \mathrm{ZrO}_{2}-\mathrm{NC}$ hybrids (Table 1, Run 1-5). The FT-IR spectra of MPTS-modified $\mathrm{ZrO}_{2}$-NCs revealed the presence of numerous hydroxyl groups as indicated by the large $\mathrm{OH}$ stretching band, ca. $3500 \mathrm{~cm}^{-1}$ (Figure $1 \mathrm{~b}$ ), primarily because of physisorbed water. The intensity of this absorption band 


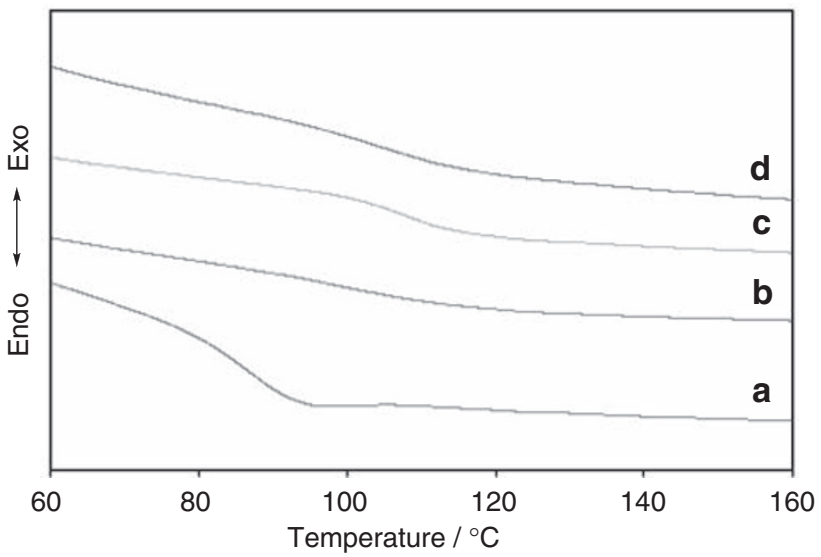

Figure 9 Differential scanning calorimetry (DSC) thermograms of (a) poly(methyl methacrylate) (PMMA) homopolymer (Run 5), (b) methyl methacrylate (MMA)/3-(methacryloxy)propyl-trimethoxysilane (MPTS)zirconium oxide $\left(\mathrm{ZrO}_{2}\right)$, molar ratio $10: 1$ (Run 3) and PMMA blend composite for (c) acetate anion-modified $\mathrm{ZrO}_{2}$ nanocrystals ( $\mathrm{ZrO}_{2}$-NCs) (Run 6) and (d) MPTS-modified $\mathrm{ZrO}_{2}$-NCs (Run 7)

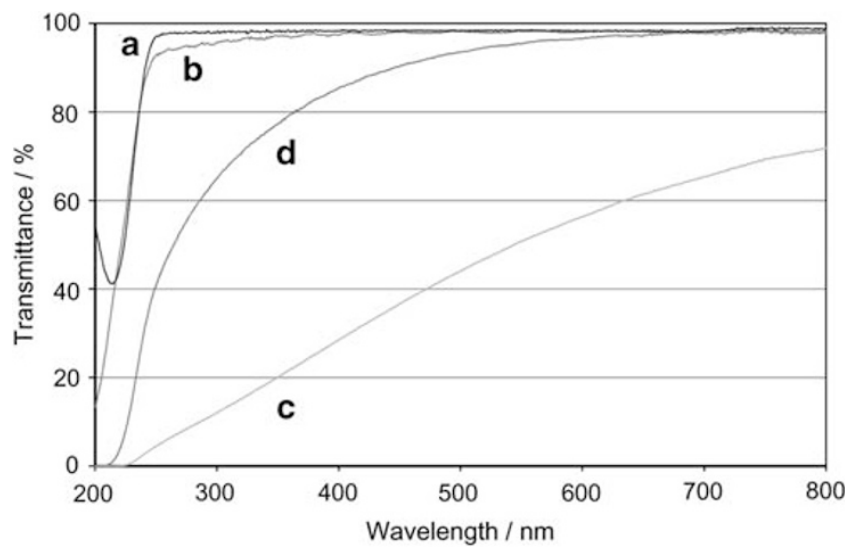

Figure 10 Thermogravimetric analysis (TGA) traces of (a) poly(methyl methacrylate) (PMMA) homopolymer (Run 5), (b) methyl methacrylate (MMA)/3-(methacryloxy)propyl-trimethoxysilane (MPTS)-zirconium oxide $\left(\mathrm{ZrO}_{2}\right)$, molar ratio of 10:1 (Run 3) and PMMA blend composite for (c) acetate anion-modified $\mathrm{ZrO}_{2}$ nanocrystals $\left(\mathrm{ZrO}_{2}\right.$-NCs) (Run 6) and (d) MPTSmodified $\mathrm{ZrO}_{2}-\mathrm{NCs}$ (Run 7).

gradually decreased with an increase in polymerized PMMA content, suggesting that $\mathrm{PMMA} / \mathrm{ZrO}_{2}-\mathrm{NC}$ hybrids harbor an increased hydrophobicity (Figured $8 \mathrm{c}$ and d). In the FT-IR spectra of PMMA/ZrO $2_{2}^{-}$ $\mathrm{NC}$ hybrids, the absorption band referring to the $\mathrm{C}=\mathrm{C}$ bond at $1637 \mathrm{~cm}^{-1}$ is also present. These bands are visible in the spectra shown in Figures $8 \mathrm{a}$ and $\mathrm{b}$, but they are not seen in those shown in Figures $8 \mathrm{c}-\mathrm{e}$, implying the complete polymerization of MMA monomers and MPTS moieties. The incomplete polymerization of MMA and MPTS-modified $\mathrm{ZrO}_{2}$-NCs in the samples shown in Figures $8 \mathrm{a}$ and $\mathrm{b}$ is probably the result of a low MMA monomer concentration. Further optimization of the polymerization condition (such as polymerization temperature, polymerization time, initiator concentration, and so on) is needed.

The thermal properties of hybrids and blend composites were examined by differential scanning calorimetry (Figure 9) and TGA (Figure 10). The PMMA homopolymer (Run 5) had a glass transition

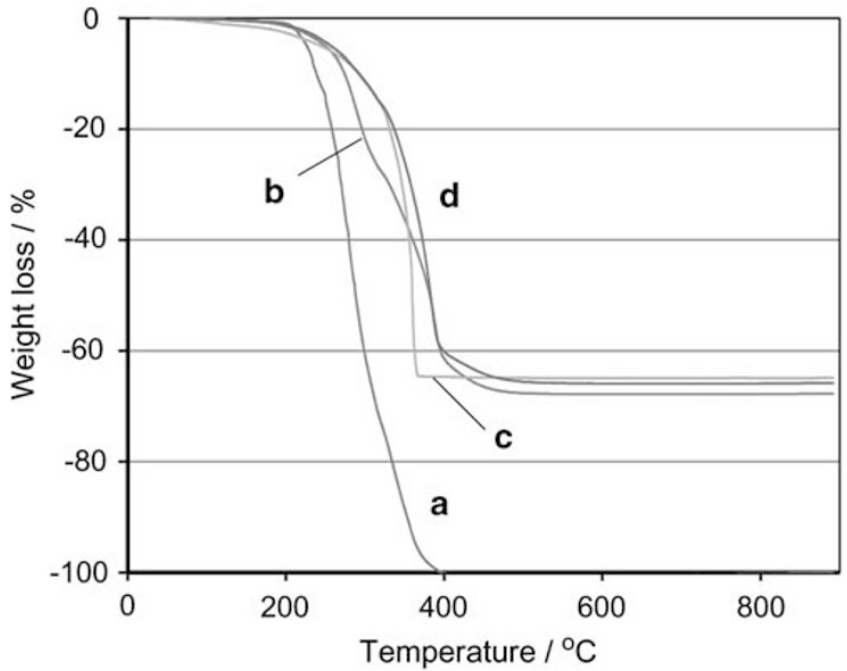

Figure 11 Optical transmittance of (a) poly(methyl methacrylate) (PMMA) homopolymer (Run 5), (b) methyl methacrylate (MMA)/3-(methacryloxy) propyl-trimethoxysilane (MPTS)-zirconium oxide $\left(\mathrm{ZrO}_{2}\right)$, molar ratio of $10: 1$ (Run 3) and PMMA blend composite for (c) acetate anion-modified $\mathrm{ZrO}_{2}$ nanocrystals ( $\mathrm{ZrO}_{2}$-NCs) (Run 6) and (d) MPTS-modified $\mathrm{ZrO}_{2}$-NCs (Run 7).

temperature $\left(T_{\mathrm{g}}\right)$ of $78.6^{\circ} \mathrm{C}$. The $\mathrm{PMMA} / \mathrm{ZrO}_{2}-\mathrm{NC}$ hybrid (Table 1 , Run 3) and blend composites (Table 2, Run 6,7) had a $T_{\mathrm{g}}$ that was higher than that of the PMMA homopolymer. These results indicate that $\mathrm{ZrO}_{2}$-NCs serve as an effective inhibitor for segmental mobility of PMMA.

The thermal stabilities of hybrids and blend composites were also studied with TGA. The weight loss observed in the PMMA/ZrO $\mathrm{Z}_{2}-\mathrm{NCs}$ hybrid (Figure 10b) was shifted to a higher temperature compared with that of the PMMA homopolymer (Figure 10a). This implies that $\mathrm{ZrO}_{2}$-NCs were successfully incorporated into the hybrid material network. In general, the stage of weight loss is similar to that of the homopolymer (Table 1 , Run 5), starting at $\sim 200^{\circ} \mathrm{C}$ and ending at $450{ }^{\circ} \mathrm{C}$, which is probably because of the structural decomposition of polymers. From the curve shown in Figure 10c, the weight loss of the blend composite (Table 2, Run 6) occurred below $200^{\circ} \mathrm{C}$, which is attributed to the thermal decomposition of acetate anion. Rapid weight loss near $350^{\circ} \mathrm{C}$ is attributed to the burning of organic moieties. In contrast, the PMMA- and MPTS-modified $\mathrm{ZrO}_{2}-\mathrm{NC}$ blend composite showed high thermal stability at high temperature (Figure 10d). This could be due to the formation of stabilized organic moieties by the agglomeration of $\mathrm{ZrO}_{2}$-NCs. Results confirm that the thermal properties of PMMA were improved by hybridization with $\mathrm{ZrO}_{2}$-NCs.

Optical transparency of PMMA/Z $\mathrm{rO}_{2}-\mathrm{NC}$ hybrid or blend composite films was characterized by collecting ultraviolet-visible spectra. Figure 11 shows the optical transmittance of a quartz glass substrate coated with hybrid or blend composite films. The transparency of the $\mathrm{PMMA} / \mathrm{ZrO}_{2}-\mathrm{NC}$ hybrid (Run 3) is similar to that of the PMMA homopolymer (Run 5), with the transmittance of the film above $95 \%$ in the visible region. The high transparency of the hybrid material in the visible region provides further evidence that $\mathrm{ZrO}_{2}$-NCs in the PMMA matrix are nanoscale and well dispersed. On the other hand, a low optical transmittance of blend composites was observed because of the light scattering arising from phase separation of PMMA and surface-modified $\mathrm{ZrO}_{2}-\mathrm{NCs}$, which was also observed in SEM images (Figures $5 \mathrm{c}$ and $\mathrm{d}$ ). 
Table 4 Refractive indices of $\mathrm{PMMA} / \mathrm{ZrO}_{2}-\mathrm{NC}$ hybrids ${ }^{\mathrm{a}}$

\begin{tabular}{lcccc}
\hline Run & 2 & 3 & 4 & 5 (PMMA) \\
\hline Refractive index (at 594 nm) & 1.53407 & 1.52317 & 1.50359 & 1.48829
\end{tabular}

Abbreviations: PMMA, poly(methyl methacrylate); $\mathrm{ZrO}_{2}-\mathrm{NC}$, zirconium oxide nanocrystal.

${ }^{a}$ Measured by prism coupler.

The refractive indices of the transparent hybrid and PMMA homopolymer films (Run 3-5), as determined by a prism coupler, are shown in Table 4. The refractive index at $594 \mathrm{~nm}$ of the PMMA/ $\mathrm{ZrO}_{2}-\mathrm{NC}$ hybrid film increased from 1.488 to 1.534 when the weight content of $\mathrm{ZrO}_{2}$-NCs was increased from $0 \mathrm{wt} \%$ (Run 5) to $38.8 \mathrm{wt} \%$ (Run 3). The increase in the $\mathrm{ZrO}_{2}$ component results in a linear increase in the refractive index. Thus, the refractive index can be tuned by manipulating this parameter, as shown in Table 4 . In this paper, we used $\mathrm{ZrO}_{2}$ crystals with $3 \mathrm{~nm}$ as an inorganic component, so that a hybrid material with not only high transparency but also high refractive index could be obtained through the hybridization of PMMA- and MPTS-modified $\mathrm{ZrO}_{2}$-NCs. These results show the excellent optical properties of $\mathrm{PMMA} / \mathrm{ZrO}_{2}-\mathrm{NC}$ hybrids, which is the most important characteristic when considering application in optical devices.

\section{CONCLUSION}

Transparent and homogeneous hybrid materials were prepared from PMMA- and MPTS-modified $\mathrm{ZrO}_{2}$-NCs, which were used as macromonomers in grafting from polymerization of MMA. FT-IR confirmed that inorganic and organic moieties were covalently bonded. $\mathrm{ZrO}_{2}$-NCs were homogeneously dispersed in polymerized hybrid sols and PMMA bulk hybrids. Hybrid films retained good optical transparency because of the formation of nanometer miscibility and good affinity between PMMA and $\mathrm{ZrO}_{2}$-NCs compared with that of $\mathrm{PMMA} / \mathrm{ZrO}_{2}-\mathrm{NC}$ blend composites. Owing to their excellent optical properties and high thermal stability, $\mathrm{PMMA} / \mathrm{ZrO}_{2}-\mathrm{NC}$ hybrids have great potential for application in optical and mechanical fields.

1 Novak, B. M. Hybrid nanocomposite materials—between inorganic glasses and organic polymers. Adv. Mater. 5, 422-433 (1993).

2 Schubert, U., Husing, N. \& Lorenz, A. Hybrid inorganic-organic materials by sol-gel processing of organofunctional metal alkoxides. Chem. Mater. 7, 2010-2027 (1995).

3 Wen, J. \& Wilkes, G.L. Organic/inorganic hybrid network materials by the sol-gel approach. Chem. Mater. 8, 1667-1681 (1996).

4 Schmid, G., Maihack, V., Lantermann, F. \& Peschel, S. Ligand-stabilized metal clusters and colloids: properties and applications. J. Chem. Soc. Dalton Trans. 589-595 (1996).

5 Beecroft, L. L. \& Ober, C. K. Nanocomposite materials for optical applications. Chem Mater. 9, 1302-1317 (1997)

6 Mucic, R. C., Storhoff, J. J., Mirkin, C. A. \& Letsinger, R. L. DNA-directed synthesis of binary nanoparticle network materials. J. Am. Chem. Soc. 120, 12674-12675 (1998).

7 Bohren, C. F. \& Huffman, D. R. Absorption and Scattering of Light by Small Particles (Wiley: New York, 1983).

8 Wei, Y., Wang, W., Yeh, J. M., Wang, B., Yang, D. \& Murray, J. K. Jr. Photochemical synthesis of polyacrylate-silica hybrid sol-gel materials catalyzed by photoacids. Adv. Mater. 6, 372-374 (1994).

9 Wei, Y., Jin, D., Yang, C. C. \& Wei, G. A fast convenient method to prepare hybrid sol-gel materials with low volume-shrinkages. J. Sol-Gel Sci. Tech. 7, 191-201 (1996).

10 Wei, Y., Jin, D., Brennan, D. J., Rivera, D. N., Zhuang, Q., DiNardo, N. J. \& Qiu, K. Atomic force microscopy study of organicinorganic hybrid materials. Chem. Mater. 10, 769-772 (1998).

11 Wang, Q., Liu, N., Wang, X., Li, J., Zhao, X. \& Wang, F. Conductive hybrids from waterborne conductive polyaniline and (3-glycidoxypropyl)trimethoxysilane. Macromolecules 36, 5760-5764 (2003).

12 Matsuura, Y., Miura, S., Naito, H., Inoue, H. \& Matsukawa, K. Nanostructured polysilane-titania hybrids and their application to porous titania thin films. J. Organomet. Chem. 685, 230-234 (2003).
13 Chujo, Y., Ihara, E., Kure, S. \& Saegusa, T. Synthesis of triethoxysilyl-terminated polyoxazolines and their cohydrolysis polymerization with tetraethoxysilane. Macromolecules 26, 5681-5686 (1993).

14 Chujo, Y., Matsuki, H., Kure, S., Saegusa, T. \& Yazawa, T. Control of pore-size of porous silica by means of pyrolysis of an organic-inorganic polymer hybrid. J. Chem. Soc. Chem. Commun. 635-636 (1994).

15 Tamaki, R., Samura, K. \& Chujo, Y. Synthesis of polystyrene and silica gel polymer hybrids via $\partial-\partial$ interactions. Chem. Commun. 1131-1132 (1998).

16 Tamaki, R. \& Chujo, Y. Synthesis of polystyrene and silica gel polymer hybrids utilizing ionic interactions. Chem. Mater. 11, 1719-1726 (1999).

17 Ogoshi, T. \& Chujo, Y. Synthesis of organic-inorganic polymer hybrids utilizing amphiphilic solvent as a compatibilizer. Bull. Chem. Soc. Jpn. 76, 1865-1871 (2003).

18 Ogoshi, T. \& Chujo, Y. Synthesis of photosensitive organicinorganic polymer hybrids by utilizing caged photoactivatable alkoxysilane. Macromolecules 37, 5916-5922 (2004).

19 Ogoshi, T. \& Chujo, Y. Synthesis of organicinorganic polymer hybrids by means of hostguest interaction utilizing cyclodextrin. Macromolecules 36, 654-660 (2003).

20 Ogoshi, T., Itoh, H., Kim, K. M. \& Chujo, Y. Synthesis of organicinorganic polymer hybrids having interpenetrating polymer network structure by formation of rutheniumbipyridyl complex. Macromolecules 35, 334-338 (2002).

21 Ogoshi, T., Fujikawa, T., Bertolucci, M., Galli, G., Chiellini, E., Chujo, Y. \& Wynne, K. J. Tapping mode AFM evidence for an amorphous reticular phase in a condensationcured hybrid elastomer: $\alpha, \omega$-dihydroxypoly(dimethylsiloxane)/poly(diethoxysiloxane)/ fumed silica nanoparticles. J. Am. Chem. Soc. 126, 12284-12285 (2004).

22 Huang, Z. H. \& Oiu, K. Y. Preparation and thermal property of poly(methyl methacrylate)/silicate hybrid materials by the in-situ sol-gel process. Polym. Bull. 35, 607-613 (1995).

23 Wang, H. T., Xu, P., Zhong, W., Shen, L. \& Du, Q. Transparent poly(methyl methacrylate)/silica/zirconia nanocomposites with excellent thermal stabilities. Polym. Degrad. Stabil. 87, 319-327 (2005).

24 Coltrain, B. K., Landry, C. J. T., O'Reilly, J. M., Chamberlain, A. M., Rakes, G. A., Sedita, J. S., Kelts, L. W., Landry, M. R. \& Long, V. K. Role of trialkoxysilane functionalization in the preparation of organic-inorganic composites. Chem. Mater. 5, 1445-1455 (1993)

25 Chen, W. C. \& Lee, S. J. Synthesis and characterization of poly(methyl methacrylate)silica hybrid optical thin films. Polym. J. 32, 67-72 (2000).

26 Huang, Z. H. \& Qiu, K. Y. The effects of interactions on the properties of acrylic polymers/silica hybrid materials prepared by the in situ sol-gel process. Polymer 38, 521-526 (1997).

27 Sunkara, H. B., Jethmalani, J. M. \& Ford, W. T. Composite of colloidal crystals of silica in poly(methyl methacrylate). Chem. Mater. 6, 362-364 (1994).

28 Jethmalani, J. M. \& Ford, W. T. Diffraction of visible light by ordered monodisperse silicapoly(methyl acrylate) composite films. Chem. Mater. 8, 2138-2146 (1996).

29 Joseph, R., Zhang, S. \& Ford, W. T. Structure and dynamics of a colloidal silicapoly(methyl methacrylate) composite by ${ }^{13} \mathrm{C}$ and ${ }^{29} \mathrm{Si}$ MAS NMR spectroscopy. Macromolecules 29, 1305-1312 (1996).

30 Yu, Y. Y., Chen, C. Y. \& Chen, W. C. Synthesis and characterization of organic-inorganic hybrid thin films from poly(acrylic) and monodispersed colloidal silica. Polymer 44, 593-601 (2003).

31 Novak, B. M. \& Davies, C. 'Inverse' organic-inorganic composite materials. 2. Freeradical routes into nonsbrinking sol-gel composites. Macromolecules 24, 5481-5483 (1991).

32 Wei, Y., Bakthavatchalam, R. \& Whitecar, C.K. Synthesis of new organic-inorganic hybrid glasses. Chem. Mater. 2, 337-339 (1990)

33 Lee, L. H. \& Chen, W. C. High-refractive-index thin films prepared from trialkoxysilanecapped poly(methyl methacrylate)titania materials. Chem. Mater. 13, 1137-1142 (2001).

34 He, W., Guo, Z. G. \& Pu, Y. K. Polymer coating on the surface of zirconia nanoparticles by inductively coupled plasma polymerization. Appl. Phys. Lett. 85, 896-898 (2004).

35 Joo, J., Yu, T., Kim, Y. W., Park, H. M., Wu, F. X., Zhang, J. Z. \& Hyeon, T. Multigram scale synthesis and characterization of monodisperse tetragonal zirconia nanocrystals. J. Am. Chem. Soc. 125, 6553-6557 (2003)

36 Kinoshita, T. Method for Producing Metal Oxide Nanoparticle, JP Patent 2006-016236 (2006).

37 Otsuka, T. \& Chujo, Y. Preparation and characterization of poly(vinylpyrrolidone)/ zirconium oxide hybrids by using inorganic nanocrystals. Polym. J. 40, 1157-1163 (2008).

38 Abboud, M., Turner, M., Duguet, E. \& Fontanille, M. PMMA-based composite materials with reactive ceramic fillers Part 1.-Chemical modification and characterisation of ceramic particles. J. Mater. Chem. 7, 1527-1532 (1997).

39 Turner, M., Duguet, E. \& Labrugere, C. Characterization of silane-modified $\mathrm{ZrO}_{2}$ powder surfaces. Surf. Interface Anal. 25, 917-923 (1997).

40 Mueller, R., Kammler, H. K., Wegner, K. \& Pratsinis, S.E. OH surface density of $\mathrm{SiO}_{2}$ and $\mathrm{TiO}_{2}$ by thermogravimetric analysis. Langmuir 19, 160-165 (2003).

41 Wang, Z. W., Wang, T. J., Wang, Z. W. \& Jin, Y. J The adsorption and reaction of a titanate coupling reagent on the surfaces of different nanoparticles in supercritical $\mathrm{CO}_{2}$. J. Colloid Interface Sci. 304, 152-159 (2006).

42 De Haan, J. W., Van Den Bogaert, H. M., Ponjee, J. J. \& Van De Ven, L. J. M. Characterization of modified silica powders by fourier transform infrared spectroscopy and cross-polarization magic angle spinning NMR. J. Colloid Interface Sci. 100, 591-600 (1986) 